\title{
KONSEP HEWAN DAN PESANNYA DALAM PARIBASA DAN BABASAN SUNDA \\ Kartika
}

\author{
Balai Bahasa Jawa Barat
}

\begin{abstract}
Abstrak
Manusia dan hewan telah lama hidup berdampingan dan berinteraksi. Kedekatan hubungan hewan dan manusia dalam kehidupan ini tercermin dalam hubungan rantai makanan, alat bantu dalam sistem produksi, investasi atau kekayaan, atau sekadar sebagai peliharaan. Sama halnya, kehidupan keseharian masyarakat Sunda pun tidak dapat dilepaskan dari hewan. Secara verbal kedekatan hubungan itu tercermin pada penggunaan konsep hewan dalam paribasa dan babasan Sunda. Tulisan ini hendak mengungkap konsep hewan apa yang digunakan dalam paribasa dan babasan Sunda, serta pesan yang terkandung di dalamnya. Paribasa dan babasan Sunda yang dijadikan data dalam tulisan ini dipilih yang khusus mengandung nama atau jenis hewan dengan menggunakan teknik simak dan catat. Data kemudian diklasifikasi berdasarkan jenisnya dan kemudian dianalisis secara kualitatif. Hasil penelitian menunjukkan bahwa jenis hewan yang digunakan dalam paribasa dan babasan Sunda sangat bervariasi mulai hewan berkaki empat seperti kerbau sampai organisme mikroskopis semacam tungau. Pesan yang terkandung di dalam paribasa dan babasan Sunda itu kemudian digeneralisasi ke dalam beberapa kategori, seperti nasihat, cemoohan, deskripsi, perbuatan yang sia-sia, perasaan (takut, gelisah, senang), dan lain-lain.
\end{abstract}

Kata kunci: makna konseptual, hewan, paribasa, babasan, Sunda

\begin{abstract}
Men and animals have been living together and have interacted with each other for a very long time. Men and animals have very adjacent relationship reflected in food chain, production systems, or merely as pets. Similarly, Sundanese community's daily life is inseparable from animals. The closeness is reflected verbally within the use of animal concept in paribasa and babasan Sunda. This writing intends to reveal the kind of animal concept used in paribasa and babasan Sunda and the message conveyed within. Paribasa and babasan Sunda used in the writing as data are selected ones specially containing names or types of animals using the type refer technique. The selected data are then categorized and analyzed qualitatively. The result shows that the types of animal used in paribasa and babasan Sunda vary from four-legged animals like buffalo to microscopic organism like flea. The messages conveyed in the paribasa and babasan Sunda are generalized into several categories like advice, scorn, description, useless deeds, feelings (fear, anxiety, happiness), etc.
\end{abstract}

Keywords: conceptual meaning, animal, paribasa, babasan, Sunda 


\section{Pendahuluan}

Manusia dan hewan telah hidup berdampingan dan berinteraksi satu sama lain sejak waktu yang sangat lama. Dalam catatan sejarah, hewan memegang peranan besar dalam kehidupan manusia. Sebagai contoh, masyarakat China menganggap bahwa hewan berguna sebagai alat dan harta milik manusia. Kuda pada zaman dinasti Tang di China memiliki tempat yang sangat tinggi sebagai penanda status sosial. Oleh karena itu, kuda hanya boleh dimiliki dan dikendarai oleh para bangsawan. Tingginya nilai kuda pada masa itu ditunjukkan dengan terbitnya sebuah peraturan yang melarang para saudagar, seniman, dan rakyat kebanyakan memiliki dan menungganginya. Masyarakat China bahkan menggunakan 11 simbol hewan nyata dan 1 hewan mitos dalam sistem penanggalannya yang berulang setiap 12 tahun (shio).

Masyarakat Sunda, sebagaimana masyarakat Asia lainnya, dalam kehidupannya seharihari pun tidak dapat dilepaskan dari hewan. Sejak zaman dahulu para petani di Indonesia memanfaatkan jasa kerbau untuk membantu menyuburkan tanah. Namun, di masa kini peran kerbau telah banyak digantikan oleh traktor. Di kalangan para pecinta seni, khususnya di Kabupaten Sumedang, para seniman melatih kuda menari sehingga terciptalah tarian "Kuda Renggong". Di samping itu, para pemburu babi hutan melatih anjing secara khusus untuk dapat membantu mereka menangkap buruan yang sering merusak lahan pertanian itu. Sementara itu, di rumah-rumah kucing dipelihara untuk menjaga rumah dari gangguan tikus. Selain untuk memburu tikus, kucing yang lucu dan manja juga dapat menjadi penghibur dan pembawa suasana ceria kepada pemiliknya.

Masih banyak fungsi hewan dalam kehidupan manusia selain yang telah dipaparkan dalam paragraf di atas. Song (2004) membagi fungsi hewan ke dalam beberapa kategori, yaitu sumber pangan (diambil daging, susu, atau telurnya) dan sandang (dimanfaatkan kulitnya untuk dijadikan pakaian atau alas kaki), upeti (diberikan kepada pihak lain atau negara lain dalam rangka mempererat hubungan diplomatik atau ekonomi), persembahan kepada Tuhan atau dewa dalam upacara keagamaan (sebagai bukti penyerahan diri seorang manusia kepada Tuhannya), obat (untuk menjaga kesehatan atau menyembuhkan penyakit), pekerja (membantu petani di ladang atau kebun), peliharaan (untuk digunakan dalam perlombaan atau untuk menunjukkan status sosial), hiburan (hewan-hewan dilatih untuk menghibur manusia dalam sebuah pertunjukan sirkus), alat taruhan (dalam perjudian), eksperimen (di laboratorium), dan simbol (dijadikan lambang negara, misalnya hewan mitos seperti naga (China) dan burung garuda (Indonesia)).

Dalam perjalanan waktu, fungsi hewan-hewan itu dapat mengalami pergeseran. Hewan yang dahulunya hanya digunakan sebagai pekerja atau penarik beban, seperti kuda, lama-kelamaan bergeser fungsinya menjadi hewan peliharaan dan hanya digunakan untuk adu ketangkasan olah raga menunggang kuda atau pacuan kuda. Hewan yang dahulunya sering dikonsumsi oleh manusia ada yang dilarang dimakan karena jumlahnya yang terus menyusut sehingga pemerintah setempat menerbitkan peraturan yang melarang manusia memakannya agar hewan itu tidak punah, misalnya penyu, paus, atau beruang. Ada pula hewan yang dilarang dikonsumsi karena larangan agama tertentu, misalnya umat Muslim dilarang memakan babi, hewan bertaring, hewan ampibi, dan hewan melata, sedangkan umat Hindu dilarang mengkonsumsi sapi. 
Kedekatan hubungan hewan dan manusia secara verbal dalam kehidupan masyarakat Sunda dapat ditemukan dalam paribasa dan babasan. Secara metaforis, hewan merepresentasikan karakteristik atau sifat-sifat tertentu. Misalnya, ungkapan bahasa Sunda harigu manukeun bermakna 'dada (manusia) yang busung seperti burung'. Dalam ungkapan itu, konsep dada burung yang bentuknya bulat dan membusung digunakan untuk memperjelas deskripsi manusia yang memiliki dada yang menonjol ke depan. Paribasa dan babasan dalam bahasa Sunda digunakan oleh para leluhur untuk menyampaikan ajaran, pesan, dan nilai-nilai moral agar manusia senantiasa hidup secara selaras dalam kebaikan dan kebenaran, sesuai dengan ajaran Tuhan Yang Maha Esa.

Penelitian mengenai paribasa dan babasan Sunda pernah dilakukan oleh Djajasudarma et al. (1997) yang meneliti nilai-nilai budaya yang terkandung dalam peribahasa dan ungkapan Sunda. Penelitian itu mengkaji peribahasa dan idiom secara struktural dan membaginya ke dalam kategori nonpredikatif (frasa) dan predikatif (klausa). Kategori lain yang dibuat oleh Djajasudarma et.al adalah bahwa 600 korpus data yang digunakan dalam penelitian itu terpilah menjadi 146 data yang berupa ungkapan, 445 data yang berupa peribahasa, dan 9 data termasuk ke dalam kategori idiom. Berdasarkan pemilahan itu, tampak bahwa Djajasudarma et al. (1997:55) membuat generalisasi bahwa ungkapan cenderung memiliki struktur frasa, sedangkan peribahasa cenderung muncul dalam bentuk klausa atau kalimat (struktur predikatif). Secara semantik, idiom dibedakan dari ungkapan dan peribahasa karena memiliki makna yang berbeda dari makna masingmasing unsur leksikalnya (Djajasudarma et al.1997:57). Nilai-nilai yang diteliti adalah nilai-nilai menyangkut pemahaman yang baik (yang dipedomani), yang buruk (yang tidak dipedomani), dan yang netral (yang berlaku secara umum). Budaya yang diteliti menyangkut hubungan antara manusia dengan kehidupan, manusia dengan karya, manusia dengan manusia lain, manusia dengan alam, dan manusia dengan waktu (Djajasudarma et al. 1997:60).

Penelitian lain mengenai peribahasa Sunda pernah dilakukan oleh Juanda (2011), yang meneliti kesamaan nilai-nilai edukatif peribahasa dan ungkapan bahasa Sunda dengan nilai-nilai ajaran Islam. Dari penelitian itu ditemukan tujuh nilai edukatif dalam peribahasa Sunda yang sesuai dengan ajaran Islam, yaitu 1) nilai edukatif dalam hal berbicara, 2) nilai edukatif dalam hal menjaga hati dan pikiran, 3) nilai edukatif dalam hal tidak melupakan asal-usul dan menjaga adat yang baik, 4) nilai edukatif agar hidup saling menyayangi, tolongmenolong, dan tidak melakukan perbuatan yang dapat menimbulkan permusuhan, 5) nilai edukatif untuk taat kepada hukum dan peraturan yang berlaku, 6) nilai edukatif untuk giat bekerja, dan 7) nilai edukatif dalam hal jabatan dan kekuasaan. Dengan demikian, terlihat bahwa nilai-nilai edukatif peribahasa Sunda ternyata selaras dengan nilai-nilai kebaikan yang terkandung dalam ajaran Islam.

Dari kedua penelitian itu dapat diambil simpulan bahwa peribahasa dan ungkapan Sunda banyak mengandung nilai-nilai kehidupan. Konsep-konsep yang digunakan di dalamnya ada yang berkaitan dengan manusia, alam, tumbuhan, hewan, dan lain-lain. Namun, setakat ini belum ada penelitian yang secara khusus membahas tentang peribahasa yang berkaitan dengan hewan. Padahal, apabila kita amati pemaparan Song (2004) mengenai fungsi hewan dalam paragraf sebelumnya, cukup banyak fungsi hewan dalam kehidupan manusia. Dengan demikian, masih terdapat rumpang yang dapat diteliti tentang paribasa dan babasan bahasa Sunda, yaitu mengenai konsep hewan yang terdapat di dalamnya 
Pokok masalah yang menjadi perhatian dalam tulisan ini adalah: 1) bagaimana konsep hewan dalam paribasa dan babasan Sunda; 2) bagaimana konotasi hewan-hewan itu; dan 3) apa pesan yang terkandung dalam paribasa dan babasan Sunda yang mengandung konsep hewan. Dengan demikian, tulisan ini akan mendeskripsikan jenis-jenis hewan apa saja yang akrab dengan kehidupan masyarakat Sunda; menjelaskan konotasi hewan-hewan itu; dan mendeskripsikan pesan-pesan yang terdapat dalam paribasa dan babasan Sunda.

Tamsyah et al. (2009:9) mendefinisikan paribasa sebagai "babandingan anu jadi perlambang lakuning hirup, ngawangun hiji omongan (runtuyan kecap) anu geus puguh éntép seureuhna, geus puguh surupanana, sarta geus tangtu pokpokanana ('peribahasa adalah perbandingan yang melambangkan perilaku hidup, membangun pembicaraan yang sudah tetap susunan kata-katanya'), sedangkan babasan didefinisikan "ucapan matok nu geus puguh éntép seuruehna nu dipaké dina harti injeumanana/lain arti sajalantrahna ('ucapan yang sudah tetap dan memiliki makna pinjaman/bukan arti yang sebenarnya'). Sementara itu, Suryani (2011:52) mendefinisikan "paribasa nya éta ungkara winangun kalimah (klausa) nu kekecapanana katut susunannana geus matok, tur maksudna geus puguh, biasana ngandung harti babandingan atawa siloka lakuning hirup manusa", sedangkan "babasan nya éta sawatara susunan kecap anu hartina teu sarua jeung harti sawajarna, tapi biasana kamahpum ku saréréa, atawa ucapan maneuh anu dipaké dina harti injeuman". Dari kedua definisi itu dapat disimpulkan bahwa paribasa merupakan kelompok kata atau kalimat perlambang perilaku manusia dalam kehidupan, sedangkan babasan adalah kelompok kata yang memiliki makna kiasan atau makna yang tidak sebenarnya tetapi makna itu sudah dipahami oleh masyarakat. Namun, dalam tulisan ini keduanya tidak akan diteliti strukturnya sehingga tidak dibedakan antara paribasa dan babasan. Keduanya akan diperlakukan sebagai idiom.

Secara tradisional, definisi idiom adalah ungkapan yang maknanya berbeda dari unsur-unsur leksikal yang membentuknya. Namun, menurut Cruse (2000:37), definisi itu terlalu sederhana karena idiom setidaknya memiliki dua syarat, yaitu 1) ungkapan yang kompleks secara leksikal (terdiri atas lebih dari satu unsur leksikal), dan 2) muncul sebagai konstituen semantis tunggal. Contohnya, dalam ungkapan This will cook Arthur's goose terdiri atas unsur leksikal this, will, dan Arthur, sedangkan cook_'s goose berdiri sebagai konstituen semantis tunggal yang tidak dapat dipisahkan. Dengan kata lain, idiom memiliki karakteristik, yakni leksikal kompleks yang sederhana secara semantis.

Suatu unsur leksikal akan memiliki makna konseptual (dikenal juga sebagai makna denotatif atau kognitif) dan makna konotatif. Makna konotatif merupakan nilai komunikatif dari satu ungkapan menurut apa yang diacu, melebihi di atas isinya yang murni konseptual (Leech 2003:23). Leech (2003) memberi contoh bahwa kata wanita secara konseptual bermakna +manusia, -pria, =dewasa, sedangkan secara konotatif memiliki sifat-sifat tambahan seperti secara fisik 'berkaki dua', 'memiliki rahim'; dan secara psikis dan sosial 'suka berteman', 'memiliki naluri keibuan'; dan masih banyak lagi. Makna konotatif sangat dipengaruhi oleh budaya, masa, dan pengalaman individu. Jadi, makna konotatif relatif tidak stabil. 


\section{Metodologi}

Di pasaran terdapat beberapa buku tentang paribasa dan babasan Sunda. Namun, penulis memillih satu saja, yaitu Ngamumulé Basa Sunda: 1200 Paribasa Jeung Babasan Sunda - Undak Usuk Jeung Unak-Anik Basa Sunda. Ini dilakukan mengingat sempitnya waktu untuk memilah data dan melakukan penelitian. Data itu dianggap cukup mewakili untuk penelitian kecil ini.

Dalam buku tersebut ditemukan kurang lebih 158 paribasa dan babasan yang mengandung nama hewan. Jumlah itu adalah $10 \%$ dari jumlah keseluruhan paribasa dan babasan yang terdapat dalam buku itu. Meskipun secara kuantitatif terlihat kecil jumlahnya, keberadaannya tidak dapat diabaikan begitu saja mengingat paribasa dan babasan adalah peninggalan tradisi leluhur yang mungkin pada saat ini sudah kurang dikenal dalam kehidupan manusia modern.

Paribasa dan babasan Sunda yang dijadikan data dalam tulisan ini dipilih yang khusus mengandung nama atau jenis hewan dengan menggunakan teknik simak dan catat. Data kemudian diklasifikasi berdasarkan jenis hewannya dan kemudian dianalisis secara kualitatif.

Data dianalisis dengan cara menentukan jenis hewan dan menentukan makna konotatifnya. Makna konotatif yang diperoleh kemudian digunakan sebagai dasar untuk menentukan pesan-pesan apa yang hendak disampaikan dalam paribasa dan babasan Sunda. Pesan-pesan yang diperoleh kemudian dikelompok-kelompokkan dan dibuat generalisasinya.

\section{Hasil dan Pembahasan}

\subsection{Jenis-jenis Hewan dan Konotasinya}

Dalam pemilahan data diperoleh 158 paribasa dan babasan berunsur hewan. Hewan yang paling banyak muncul adalah harimau/macan (15), ikan (12), ayam (11), anjing (9), burung, kuda, kerbau, dan kucing (masing-masing 6), monyet dan kodok (masing-masing 5), dan udang (4). Hewan lain, seperti berang-berang, sapi, kerbau, keledai, badak, kambing, buaya, bajing, tikus, kadal, merak, merpati, kuntul, aeud (sejenis burung), aul (sejenis burung), jogjog (sejenis burung), toéd (sejenis burung berkicau), belalang, gaang (sejenis serangga), kutu busuk, lalat, rayap, belatung, kutu beras, belut, remis, kerang, dan umang hanya muncul satu kali. Hewan yang muncul dua kali di antaranya adalah kelelawar buah, burung hantu, ulat, lintah, tungau, lebah, siput sawah, dan kura-kura. Hewan lain yang muncul tiga kali adalah banteng, musang, bebek, elang, cacing, kunang-kunang, semut, dan kumbang. Dari pemaparan itu terlihat bahwa hewan-hewan yang dikenal masyarakat Sunda sangat bervariasi dari yang berukuran besar seperti kerbau atau kuda hingga yang kecil macam tungau dan kutu busuk; yang buas seperti elang dan harimau hingga yang tampak tak berbahaya macam cacing dan ulat; semuanya tak luput dari pengamatan masyarakat Sunda. Hewan-hewan seperti aul (makhluk mitos yang suka meludah) dan jogjog (sejenis burung berkicau), mulai terdengar asing di telinga masyarakat Sunda modern. Hewanhewan itu hanya dapat ditemukan di buku-buku paribasa dan babasan atau dalam kamus bahasa Sunda.

Harimau atau macan paling banyak digunakan dalam paribasa dan babasan Sunda. Hewan itu memiliki konotasi 'menakutkan', 'binatang yang kuat', 'berbahaya', 'berkuasa', 'berkaitan dengan status yang tinggi', dan 'galak'. Contohnya: Cicing dina sihung maung 
'nganjrek di jelema anu bisa nyusahkeun atawa nyilakakeun ka diri urang (mengabdi (bekerja) pada orang yang disegani sehingga ikut dihargai oleh orang lain, walaupun pada akhirnya hanya akan menyusahkan)'. Dari paribasa itu terlihat bahwa pihak yang dianggap berkuasa/berwenang dilambangkan dengan sihung maung 'taring macan' yang dapat merobek atau menggigit mangsanya sewaktu-waktu. Orang yang berkuasa dapat berbuat apa saja sesuka hatinya kepada orang-orang yang berada di bawah kekuasaannya disebabkan oleh kekuasaannya itu. Contoh lain adalah Ngalintuhan maung kuru 'néangan pibahayaeun' 'mencari bahaya, melakukan pekerjaan yang akan membahayakan'. Dalam paribasa itu harimau memiliki konotasi bahaya.

Ikan menempati urutan kedua dan memiliki konotasi 'simbol rezeki', 'lemah/tidak berdaya', dan 'simbol usaha'. Dalam paribasa Moal jauh laukna 'moal hésé piuntungeuna (tidak akan sulit mendapatkan keuntungannya)', ikan melambangkan peruntungan atau rezeki. Bahkan dalam masyarakat Sunda ada kepercayaan bahwa apabila seseorang bermimpi mendapatkan ikan besar, itu berarti orang tersebut akan mendapatkan rezeki besar yang tidak disangka-sangka.

Hewan berikutnya yang banyak muncul dalam paribasa dan babasan Sunda adalah ayam. Ayam memiliki konotasi 'selalu lapar', 'penakut/pengecut', 'canggung', 'berisik', dan 'lemah'. Contohnya paribasa Caréham hayameun 'gampang pisan laparna (mudah sekali lapar)' menunjukkan bahwa ayam adalah hewan yang selalu kelaparan. Apabila kita perhatikan ayam yang berkeliaran di halaman selalu mengais-ngais tanah mencari biji, remah-remah, atau serangga tanah untuk dimakan. Jadi, ayam memang tidak pernah berhenti makan.

Kuda termasuk binatang yang banyak disebut dalam paribasa dan babasan Sunda. Kuda memiliki konotasi di antaranya 'simbol rezeki', 'simbol hawa nafsu', 'harta kekayaan', 'bersifat liar', 'barang titipan', dan 'sumber kebanggaan'. Dalam paribasa Adéan ku kuda beureum 'beunghar ku barang titipan atawa ginding ku pakéan batur (sombong dengan barang pinjaman atau barang milik orang lain; bergaya, bertingkah, atau bersolek dengan barang pinjaman)', barang titipan atau barang milik orang lain dilambangkan dengan kuda beureum 'kuda merah' yang mahal harganya. Hanya orang berhartalah yang mampu memiliki kuda beureum sehingga memilikinya menimbulkan kebanggaan.

Monyet cukup sering muncul dalam paribasa Sunda. Misalnya dalam paribasa Monyét dibéré séséngkéd 'dibéré kasempatan, komo ngahanakeun (kana kalakuan goréng)' 'semakin menjadi-jadi (melakukan pekerjaan buruk) karena diberi kesempatan', monyet memiliki konotasi negatif, yaitu tidak bisa dipercaya. Selain itu, monyet juga memiliki konotasi lain, yaitu kelicikan, kelincahan, dan kebodohan.

Anjing juga termasuk hewan yang banyak muncul dalam paribasa dan babasan Sunda. Salah satu paribasa Sunda yang berkaitan dengan anjing berbunyi Pageuh kancing loba anjing 'taki-taki mageuhan tulak bisi aya bancang pakéwuh' 'bersiap sedia mengunci rapat pintu rumah khawatir ada mara-bahaya'. Dalam paribasa itu, anjing memiliki konotasi negatif, yaitu identik dengan marabahaya. Dalam paribasa lain yang berbunyi Nulungan anjing kadempét atau Nulungan anjing tiselap 'nulungan jalma nu teu boga pisan rasa tumarima' 'kebaikan dibalas keburukan', anjing memiliki konotasi negatif, yaitu kehinaan. Selain itu, konotasi yang muncul dari hewan anjing di antaranya adalah lambang kelemahan, penampilan fisik yang buruk (beuteung anjingeun 'perut besar'), kewaspadaan, dan kebodohan. 


\subsection{Pesan-pesan dalam Paribasa dan Babasan Sunda}

Paribasa dan babasan adalah petuah leluhur untuk masyarakat yang akan datang. Paribasa dan babasan seharusnya menjadi pegangan masyarakat Sunda dalam menjalankan kehidupannya. Dari pengelompokan paribasa dan babasan berdasarkan pesannya, diperoleh kategori-kategori berikut ini.

1. Cemoohan

Salah satu contohnya adalah paribasa Kawas cucurut kaibunan 'ngeunaan ka jelema anu goréng patut rupana, matak sareukseuk panon anu nénjo (tampak jelek (rupanya) serta patut dikasihani)' menjelaskan penampilan seseorang yang tidak sedap dipandang sehingga menjadi cemoohan. Dalam hal ini, hewan yang dijadikan perlambang adalah cucurut 'tikus curut' yang memang dianggap sebagai makhluk yang menjijikkan. Contoh lain paribasa dan babasan yang mengandung cemoohan adalah Kawas careuh bulan 'diwedak kandel teuing' 'memakai bedak yang terlalu tebal'.

2. Nasihat

Pesan yang berupa nasihat memiliki beberapa subkategori, yaitu nasihat tentang kebaikan yang dibalas dengan keburukan, nasihat untuk selalu berusaha, nasihat untuk selalu berhati-hati, nasihat untuk tidak mempercayai kabar burung, nasihat untuk tidak menantang bahaya, nasihat untuk kembali ke asal, nasihat untuk kerukunan, nasihat untuk menuntaskan pekerjaan, dan nasihat untuk mawas diri. Berikut ini beberapa contoh di antaranya.

a. Ungkapan Pageuh kancing loba anjing 'taki-taki mageuhan tulak bisi aya bancang pakéwuh (bersiap sedia mengunci rapat pintu rumah khawatir ada mara-bahaya)' berisi nasihat agar selalu berhati-hati. Anjing yang dalam masyarakat Sunda memiliki konotasi negatif digunakan sebagai perlambang keburukan atau dalam hal ini marabahaya. Oleh karena itu, manusia harus senantiasa waspada apabila berhadapan dengan anjing.

b. Ungkapan Sireum ogé katincak-tincak teuing mah tangtu ngégél 'nu leutik tur hina ogé ari dikaya-kaya teuing mah tangtu ngalawan, ngabéla diri' 'orang miskin dan hina pun bila terlalu dianiaya tentu akan melawan' berisi nasihat agar tidak bertindak sewenang-wenang terhadap orang lain yang dianggap lebih lemah karena pihak yang tertindas boleh jadi akan melawan sekuat tenaga.

c. Nasihat agar tidak membalas kebaikan dengan keburukan terdapat dalam ungkapan Ngingu kuda kuru, ari geus lintuh nyépak 'miara atawa ngaméménan jalma walurat, ari geus senang jadi cucungah' 'memelihara atau membantu orang yang serbakekurangan, namun setelah dia kaya (hidup senang) menjadi pongah atau kurang ajar'.

d. Nasihat agar tidak mudah mempercayai kabar burung terdapat dalam ungkapan Uncal kaauban surak 'ngadéngé béja tacan sidik tuluy diandelkeun enya baé (kakara ngadéngé béja tuluy percaya)' 'baru mendengar kabar (berita) dari orang lain sudah dipercaya'.

3. Pujian

Kategori pujian ini diperoleh dari ungkapan-ungkapan yang mengandung pesan 
memuji atau memberi penghargaan terhadap suatu perbuatan atau keadaan. Berikut ini adalah beberapa contohnya.

a. Indung lembu bapa banténg 'turunan gagah, beunghar, ménak ti indung ti bapa' 'keturunan orang gagah, kaya raya, bangsawan dari ibu maupun ayah'. Ungkapan itu merupakan pujian terhadap seseorang yang berasal dari keturunan yang baik dengan status sosial yang tinggi.

b. Lolondokan 'bisa ngaluyukeun diri jeung kaayaan lingkungan atawa kaayaan jaman' 'bisa menyesuaikan diri dengan lingkungan atau keadaan jaman'. Ungkapan ituadalah pujian kepada seseorang yang memiliki sifat mudah bergaul dan menyesuaikan diri dengan lingkungannya dengan harmonis, yang dilambangkan dengan hewan bunglon. Bunglon adalah hewan yang memiliki mekanisme pertahanan diri berupa kemampuan untuk menyamar menyerupai keadaan di sekelilingnya.

c. Sakuru-kuru(na) lembu saregéng-regéngna banténg 'samiskin-miskinna ogé pangagung mah tangtu baé moal miskin cara somah nu teu boga' 'semiskinmiskinnya orang yang mempunyai jabatan tentunya tidak semiskin rakyat jelata yang tidak punya apa-apa'. Ungkapan itu mengandung pujian bahwa seseorang yang pada dasarnya bermartabat tidak akan kehilangan martabatnya atau wibawanya meskipun ia jatuh miskin.

4. Perbuatan sia-sia

Terdapat banyak sekali ungkapan yang menunjukkan perbuatan sia-sia. Berikut ini adalah beberapa contohnya.

a. UngkapanNgadagoan kudatandukan'miharep perkaraanumustahil (mengharapkan perkara yang mustahil)' menunjukkan suatu pengharapan yang mustahil karena kuda bukan hewan bertanduk. Oleh karena itu, mengharapkan bahwa pada suatu saat kuda akan tumbuh tanduknya adalah perbuatan yang sia-sia saja karena tidak akan mungkin terjadi.

b. Ngarep-ngarep kalangkang heulang 'ngarep-ngarep hiji perkara anu kacida banggana jeung susah pihasileunana' 'mengharapkan sesuatu hal yang begitu susah untuk diraih'. Bayangan adalah suatu benda yang hanya dapat dilihat tetapi tidak dapat disentuh apalagi disimpan. Sementara itu, elang adalah hewan yang biasanya terbang sangat tinggi sehingga bayangannya jarang sekali tampak kecuali ketika ia sedang menukik hendak menyerang mangsanya. Oleh karena itu, harapan agar dapat memiliki bayangan sang elang adalah sebuah kesia-siaan.

c. Mapatahan naék ka monyét 'mapatahan ka nu leuwih pinter' 'mengajari orang yang lebih pandai'. Monyet adalah hewan yang sangat lincah dan pandai memanjat. Oleh karena itu ia tidak perlu diajari untuk memanjat pohon atau yang lainnya.

5. Deskripsi

Sebagian kecil paribasa dan babasan tidak memiliki pesan yang hendak disampaikan. Yang terdapat di dalamnya adalah semata-mata deskripsi suatu fakta yang umum seperti beberapa contoh berikut ini. 
a. Kawas bayah kuda 'belél pisan' 'sangat lusuh, misalnya kain'. Bayah adalah organ tubuh tempat mencerna makanan. Organ pencernaan milik kuda itu apabila dilihat dengan mata telanjang tampak seperti kain lusuh yang warnanya sangat pudar.

b. Leleyep asu 'acan saré enya' 'belum benar-benar tidur'. Asu atau anjing adalah hewan penjaga yang memiliki sifat sangat waspada sehingga ketika tidur pun, seekor anjing tidak benar-benar terlelap.

6. Ungkapan perasaan

Ada pula paribasa atau babasan yang tidak mengungkapkan pesan tetapi hanya mengekspresikan perasaan-perasaan tertentu, seperti rasa sedih, kecewa, menyesal, sakit, dendam, canggung atau kikuk, atau lemah. Berikut ini beberapa contohnya.

a. Kawas anjing tutung buntut 'berebet ka ditu, berebet ka dieu, kawas nu samar rasa' 'gelisah; sedang kebingungan'. Ungkapan itu melambangkan situasi yang kacau, gelisah, dan resah.

b. Ungkapan Teu puguh monyét hideungna 'teu puguh tungtungna' 'tidak menentu (tidak beres) akhirnya' mengandung pesan mengenai suatu perkara yang akhirnya tidak jelas sehingga menimbulkan kekecewaan.

c. Dikepung wakul buaya mangap 'dikepung ku musuh nu samakta pakarangna' 'dikepung oleh musuh yang lengkap persenjataannya' mencerminkan situasi yang sangat menakutkan karena menghadapi bahaya yang besar.

d. Moro julang ngaleupaskeun peusing 'ngalésotkeun barang nu geus kapimilik lantaran kabita ku nu leuwih gedé, padahal can tangtu hasil' 'melepaskan barang (sesuatu) yang telah menjadi milik kita karena tergiur oleh yang lebih besar, padahal belum tentu berhasil' membawa pesan kekecewaan karena melepaskan sesuatu yang sudah berada di genggaman karena mengharapkan hal lain yang dianggap membawa keuntungan yang lebih besar tetapi gagal diperoleh.

7. Kategori lain

Paribasa dan babasan lain yang hanya terdiri atas satu atau dua ungkapan dimasukkan ke dalam kategori lain. Yang termasuk ke dalam kategori ini, misalnya adanya niat terselubung, menjadi penghalang, sifat buruk, perbuatan tidak terpuji, kurang beruntung, berlebih-lebihan, ingin dipuji, mendapat halangan, menunggu ajal, tidak bertanggung jawab, mendapat kesulitan, dan menantang bahaya. Berikut ini adalah beberapa contohnya.

a. Élmu sapi 'samiuk (ngahiji) kana kagoréngan (bersatu (kompak) dalam hal yang kurang baik)'. Dalam paribasa Sunda, élmu sapi 'ilmu sapi' adalah suatu pelajaran tentang keburukan karena mendeskripsikan sekelompok orang yang bersatu-padu untuk melakukan perbuatan tercela. Sapi dianggap sebagai hewan yang bodoh sehingga menganut ilmu sapi tentu bermakna berpihak kepada kebodohan.

b. Jadi maung malang 'jadi panghalang (ngeunaan ka lalaki nu ngahalangan pijodoeun hiji awéwé' 'jadi penghalang (lelaki yang menghalangi bakal jodoh 
seorang perempuan' mengandung pesan adanya seseorang yang secara sengaja menghalangi tercapainya maksud pihak lain.

c. Nya picung nya hulu maung 'nu nanya jeung nu ngajawab teu sapagodos; pananya jeung jawab téh pasalia, henteu nyambung' 'yang bertanya dan yang menjawab tidak sepaham; pertanyaan dan jawabannya tidak sesuai' mengandung pesan adanya komunikasi yang tidak berjalan lancar karena tidak saling memahami.

\section{Simpulan dan Saran}

\subsection{Simpulan}

Dari pembahasan di bagian sebelumnya dapat disimpulkan sebagai berikut.

a. Konsep hewan yang digunakan dalam paribasa dan babasan Sunda sangat bervariasi mulai hewan berkaki empat seperti kerbau sampai organisme mikroskopis semacam tungau. Ini menunjukkan bahwa masyarakat Sunda sangat memperhatikan alam sekitarnya. Bukan hanya hewan yang berukuran besar saja yang terlihat jelas oleh mata yang diambil pelajarannya, melainkan hewan-hewan kecil berukuran mikroskopis pun tak luput dari kearifan masyarakat Sunda.

b. Setiap hewan yang muncul dalam paribasa dan babasan Sunda itu memiliki konotasi positif dan/atau negatif. Bahkan, satu hewan yang sama terkadang memiliki kedua konotasi itu, misalnya hewan harimau. Konotasi positifnya adalah melambangkan kekuasaan, wibawa, kekuatan, sedangkan konotasi negatifnya adalah melambangkan marabahaya serta sifat buas dan galak.

c. Pesan yang terkandung di dalam paribasa dan babasan Sunda itu dapat dimasukkan ke dalam beberapa kategori, yaitu cemoohan, nasihat, pujian, perbuatan yang siasia, deskripsi, ungkapan perasaan, dan lain-lain.

\subsection{Saran}

Hasil penelitian mengungkapkan bahwa konsep hewan digunakan sebagai perlambang oleh para leluhur agar masyarakat Sunda lebih mudah memahami nilai-nilai baik dan buruk, apa yang boleh dilakukan dan tidak boleh dilakukan, serta agar manusia senantiasa berjalan sesuai ketentuan Tuhan dan norma-norma kemasyarakatan. Dengan hidup sesuai dengan ketentuan Tuhan dan norma kemasyarakatan, manusia akan hidup dalam kedamaian dan keselarasan.

Untuk lebih menggali nilai-nilai kebaikan dan pelajaran yang terkandung dalam paribasa dan babasan, tentu perlu diadakan penelitian lanjutan. Ada baiknya dilakukan penelitian tentang konsep tumbuhan yang digunakan dalam paribasa dan babasan Sunda untuk mengetahui bagaimana masyarakat Sunda mempersepsi alam dan lingkungannya melalui persepsi mereka tentang tumbuhan. 


\section{Daftar Pustaka}

Cruse, Alan. 2000. Meaning in Language: An Introduction to Semantics and Pragmatics. Oxford: Oxford University

Djajasudarma, T. Fatimah et al. 1997. Nilai Budaya dalam Ungkapan dan Peribahasa Sunda. Jakarta: Pusat Pembinaan dan Pengembangan Bahasa Departemen Pendidikan dan Kebudayaan.

Juanda, Asep. 2011. "Kesamaan Nilai-nilai Edukatif dalam Peribahasa Bahasa Sunda dengan Ajaran Islam (Sebuah Kajian Intertekstualitas)". Dalam M. Abdul Khak et al. (ed.). Kekayaan Budaya dalam Bahasa Ibu. Bandung: Penerbit ITB.

Nugraha. 2010. Ngamumulé Basa Sunda: 1200 Paribasa jeung Babasan Sunda - Undak Usuk Jeung Unak-Anik Basa Sunda. Bandung: CV Yrama Vidya Bandung.

Partana, Paina. 2003. Semantik. Diterjemahkan dari Geoffrey Leech. Semantics oleh Paina Partana. Yogyakarta: Pustaka Pelajar.

Song, Wei. (2004, April). "Traditional Chinese Culture \& Animals." Ditulis untuk International Animal Law Conference, April 2-4 2004, San Diego. Diunduh 7 Juni 2012 dari http://www.animallaw.info/nonus/articles/ arcnweiculturalatt2005.htm.

Suryani, Elis. 2011. Calakan Aksara, Basa, Sastra, Katut Budaya Sunda. Bogor: Ghalia Indonesia.

Tamsyah, Budi Rahayu et al. 2009. 1000 Babasan jeung Paribasa Sunda. Bandung: Pustaka Setia. 